EESTI NSV TEADUSTE AKADEEMIA TOIMETISED. 29. KOIDE

GEOLOOGIA, 1980, NR. 1

ИЗВЕСТИЯ АКАДЕМИИ НАУК ЭСТОНСКОИ ССР. ТОМ 29

ГЕОЛОГИЯ, 1980, № 1

А. ЮРГАИТИС, Г. ЮОЗАПАВИЧЮС,

B. КЛЕПИКОВ, В. КАЛМ

\title{
О ГРАНУЛОМЕТРИЧЕСКОЙ ДИФФЕРЕНЦИАЦИИ ЧЕТВЕРТИЧНЫХ ПЕСЧАНО-ГРАВИИНЫХ И ПЕСЧАНЫХ ОТЛОЖЕНИЙ ПРИБАЛТИКИ И СЕВЕРНОЙ БЕЛОРУССИИ
}

Гранулометрический состав рыхлых четвертичных отложений служит важной литологической характеристикой качества песков и песчаногравийных отложений. Цели исследований и характер используемой аппаратуры предопределяют применение разных методов опробования, лабораторных исследований, обработки и интерпретации полученных данных. Все это, а также подчас неоднозначное толкование генезиса некоторых разновидностей флювиогляциальных отложений затрудняет использование и обобщение обширного материала по гранулометрическому составу четвертичных песков и песчано-гравийной смеси на территории Прибалтики и Северной Белоруссии (Горелик и др., 1961; Куршс, 1963; Юргайтис, 1969; Раукас и др., 1971; Левков, Тихонов, 1972; Даниланс, 1973; Матвеев, 1976; Биргер и др., 1977; Раукас, 1978).

Для достоверного выяснения различий между неоднородными по гранулометрическому составу четвертичными песчано-гравийными и песчаными отложениями необходимо использовать единую методику исследования, наборы сит с одинаковой дробностью и единую статистическую обработку полученных данных. Кроме того, очень важно во всех случаях точно определять генезис отложений. Поэтому при подготовке настоящей работы мы опирались главным образом на результаты собственных полевых и лабораторных исследований.

Для детальных литологических исследований на территории Прибалтики и Северной Белоруссии выбрано 85 эталонных карьеров, которые охватывают почти все изученные генетические разновидности отложений. Примерно половина из их находится в Литве, $14-$ в Латвии и Эстонии, 17 - в Северной Белоруссии. Ввиду отсутствия карьеров и обнажений на побережье Балтийского моря в Литовской ССР большая часть песков пляжа, флювиогляциальных террас, эоловых и лимногляциальных образований опробована в мелких шурфах, а пробы прибрежно-морских (подводного склона до глубины 5 м) песков отобраны песчано-гравийным тралом (Linčius, Uginčius, 1972). Из каждого карьера отбирали не меньше чем 6 наиболее характерных проб песчано-гравийного материала и песков. Всего гранулометрический состав изучили в 226 пробах песчано-гравийного материала и 1595 образцах песков. Пробы брали бороздовым способом через всю мощность слоя. Образцы просеивали стандартными наборами сит (рис. 1 и 3). Песчаную часть породы просеивали ротапом после предварительного отмучивания частиц мельче 0,01 мм. Гранулометрические коэффициенты рассчитывали аналитическим способом на ЭВМ, а степень изменчивости содержания отдельных размерных фракций отложений опреде- 

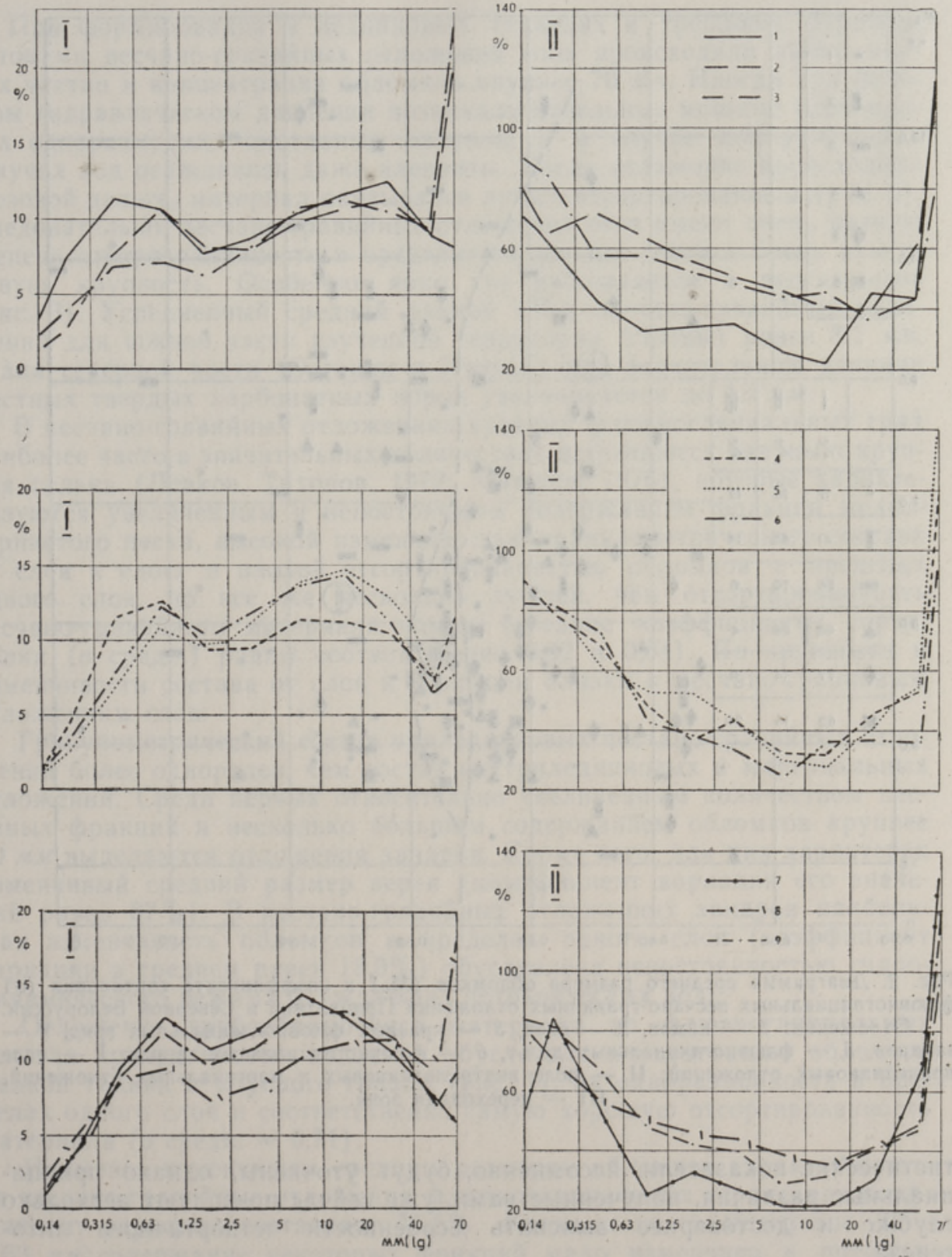

Рис. 1. Распределение усредненного гранулометрического состава (I) и коэффициента вариации содержания отдельных фракций (II) четвертичных песчано-гравийных отложений Прибалтики и Северной Белоруссии.

Отложения: 1 - камов (количество образцов $n=46), 2-$ озов $(n=32), 3$ - краевых флювиоглящиальных гряд $(n=45), 4$ - зандров $(n=29), 5$ - флювиогляциальных дельт $(n=48), 6$ - флювиогляциальных террас $(n=13), 7$ - аллювиальные $(n=13)$, 8 - внутриледниковые и маргинальные, 9 - приледниковые.

ленного генезиса - по стандартной программе для определения статистических характеристик распределения.

При накоплении нового фактического материала установленные ста- 


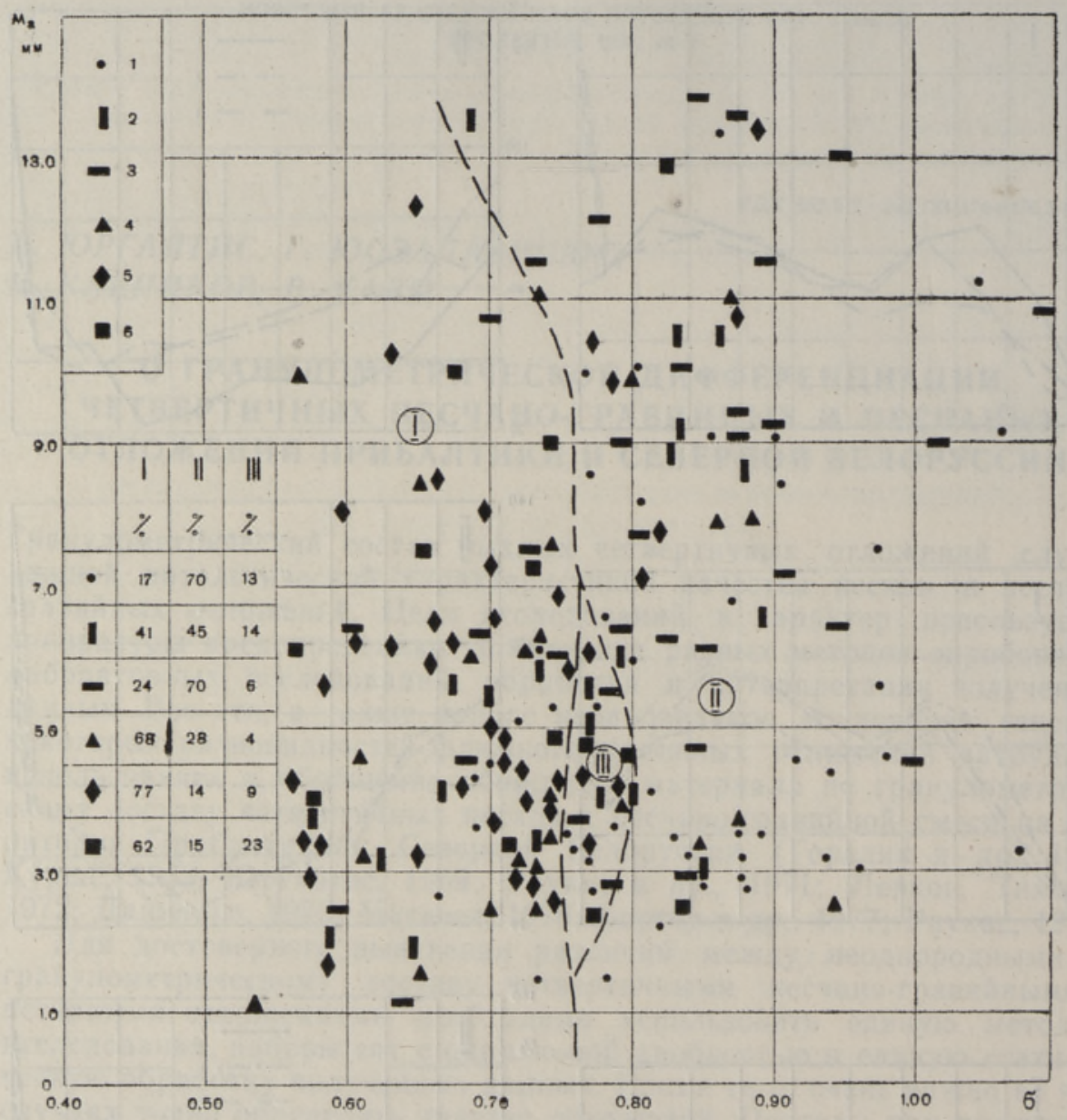

Рнс. 2. Диаграмма среднего размера обломков $\left(M_{a}\right)$ и коэффициента сортндовки (б) флювноглящиальных песчано-гравийных отложений Прибалтнки и Северной ьелоруссии.

Отложения: 1 - камов, 2 - озов, 3 - краевых флювиогляциальных гряд, 4 зандров, 5 - флювиогляциальных дельт, 6 - флювиогляциальных террас; 1 - поле прнледниковых отложений; II - поле внутриледннковых и маргинальных отложениян; III - переходная зона.

тистические показатели, несомненно, будут уточнены, однако принципиальные различия, полученные нами, уже сейчас позволяют несколько глубже и достовернее выяснить особенности четвертичного литогенеза.

Для песчано-гравийных отложений камов, по нашим данным, характерны наиболее мелкий (усредненный средний размер зерен $\left(M_{a}\right)$ равен $5,3 \mathrm{мм}$ ) и довольно постоянный от слоя к слою гранулометрический состав, повышенное содержание частиц мелкозернистого песка, незначительное количество крупной гальки, практически полное отсутствие валунов (рис. 1) и плохая отсортированность материала в пределах отдельных слоев (рис. 2). Названные особенности распределения обломков - это результат непродолжительного переноса неоднородного материала водными потоками, слабой его дифференциации и отложения во внутриледниковых водоемах с малоизменчивым гидродинамическим режимом. 
При формировании в ледниковых туннелях и трещинах бурными потоками песчано-гравийных отложений озов происходили вынос мелких частиц и концентрация обломков крупнее 70 мм. Иногда при большом гидравлическом давлении возникали отдельные мощные слои мелких одноразмерных окатанных валунов, а в случае поднруживания текучих вод осаждались даже алевриты. Когда отложение происходило в озовой дельте, материал оказывался лучше отсортированным (рис. 2). Следовательно, песчано-гравийные отложения озов имеют очень разную степень отсортированности в пределах отдельных слоев и очень изменчивую крупность. Особенно ярко это наблюдается в песках озов (рис. 3). Усредненный средний размер $\left(M_{a}\right)$ песчано-гравийных отложений для южной части изученной территории (Литвы) равен 8,1 мм, а для северной части (Эстонии и Латвии) при значительном влиянии местных твердых карбонатных пород увеличивается до 13 мм.

В песчано-гравийных отложениях краевых флювиогляциальных гряд наиболее часто в значительных количествах встречаются валуны и крупная галька (Левков, Тихонов, 1972; Матвеев, 1976), которые характеризуются увеличенным и непостоянным содержанием фракции мелкозернистого песка, высокой изменчивостью гранулометрического состава от слоя к слою и плохой отсортированностью обломков в пределах одного слоя, но все же несколько лучшей, чем отсортированность песчано-гравийного материала камов (средние коэффициенты сортировки ( $\sigma$ средн.) равны соответственно 0,82 и 0,84$)$. По крупности и изменчивости состава от слоя к слою они близки к песчано-гравийным отложениям озов.

Гранулометрический состав приледниковых песчано-гравийных отложений более однороден, чем состав внутриледниковых и маргинальных отложений. Среди первых относительно увеличенным количеством песчаных фракций и несколько бо́льшим содержанием обломков крупнее 70 мм выделяются отложения зандров. Кроме того, для них характерен изменчивый средний размер зерен (коэффициент вариации его значений равен $87 \%$ ). В песчано-гравийных отложениях зандров наибольшая изменчивость обломков в пределах одного слоя (коэффициент вариации в среднем равен $18,9 \%$ ) обусловлена непостоянностью гидродимамического режима блуждавших потоков талых вод.

Отложение грубообломочного материала во флювиогляциальных дельтах приледниковых водоемов обусловило концентрацию обломков мелкой гальки и крупного гравия (рис. 1), их одноразмерность в пределах одного слоя и соответственно самую хорошую отсортированность материала ( $\sigma$ средн. $=0,71)$.

Наименее изменчивым средним размером обломков характерґизются песчано-гравийные отложения флювиогляциальных террас, где коэф. фициент вариации составляет $51,6 \%$. Кроме того, в интервале $70-$ 0,63 мм содержание некоторых фракций мало изменчиво и преобладают фракции $20-10$ и $10-5$ мм (рис. 1). Отмеченные особенности механического состава песчано-гравийных отложений возникли благодаря Бодообильности и сравнительно постоянному гидродинамическому режиму флювногляциального долинного потока.

Bce приледниковые песчано-гравийные отложения отсортированы лучше, чем внутриледниковые и маргинальные (рис. 2). Несколько хуже из первых иногда отсортированы отложения зандров, обычно оплывневой фазы седиментации, для которых коэффициент сортировки составляет $0,85-0,9$. Приледниковые песчано-гравнйные отложения заметно мельче, чем отложения озов или краевых флювиогляциальных гряд, и крупнее, чем камов и аллювия. Усредненный средний размер зерен для 

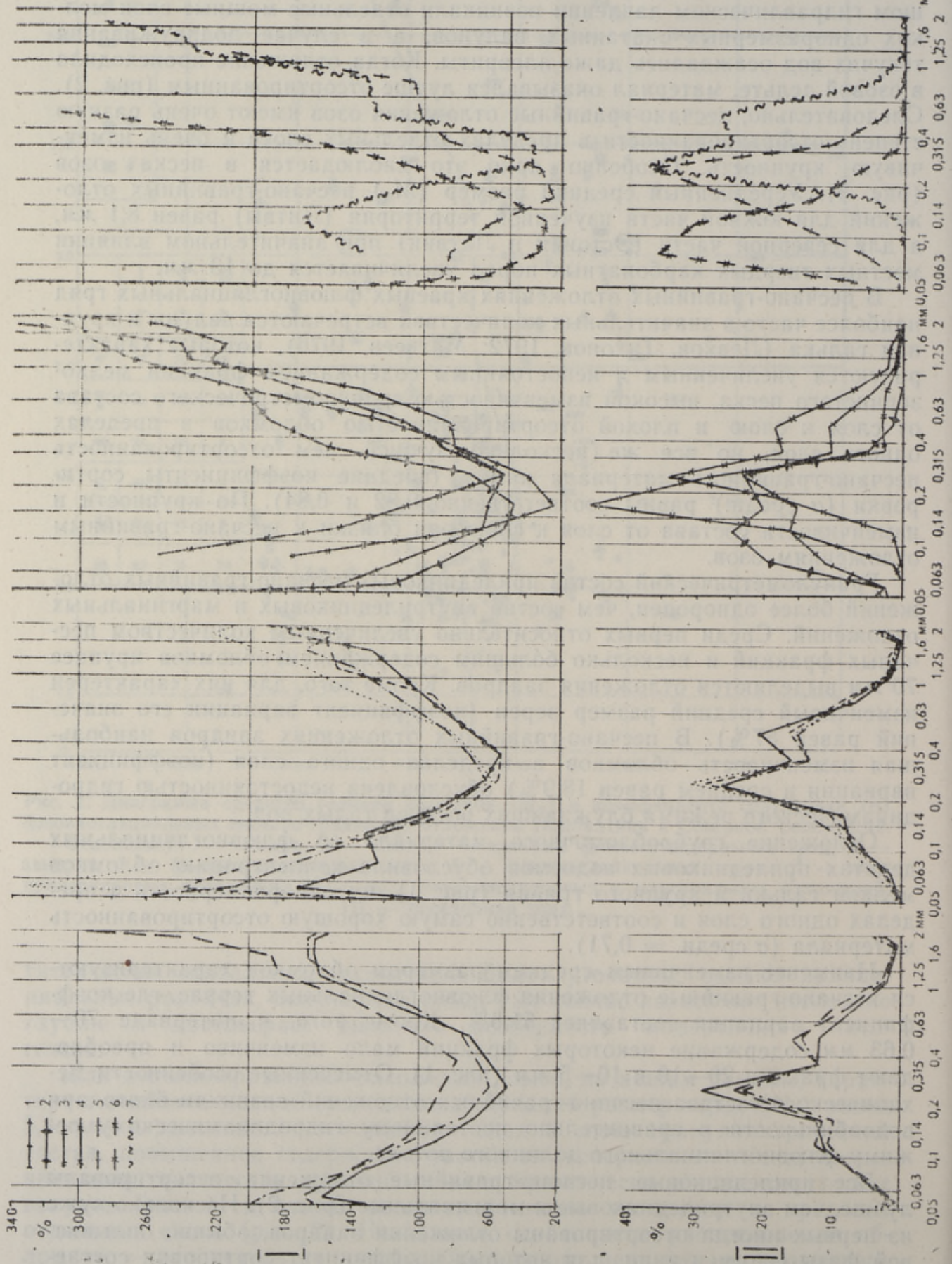
Рис. 3. Распределение коэффициента вариации содержания отдельных фракций (I) и усредненного гранулометрического состава (II) четвертичных песков Прибалтики и Северной Белоруссии.

Пески: 1 - лимнокамов $(n=67), 2$ - лимногляциальные $(n=237), 3$ - прибрежноморские $(n=99), 4$ - пляжа Балтийского моря $(n=368), 5$ - эоловые на флювиогляциальных террасах $(n=75), 6$ - эоловые на лимногляциальных равнинах $(n=46)$, 7 - эоловые морского побережья $(n=158)$. Прочие условные обозначения см. на рис. 1 .

Пр и м е ч н ие. Количество образцов песков смешанных камов $n=84$, озов $n=58$, краевых флювиогляциальных гряд $n=96$, зандров $n=99$, флювиогляциальных дельт $n=57$, флювиогляциальных террас $n=105$, аллювиальных $n=46$. Исходные данные о песках побережья Балтийского моря получены от А. Линчюса, за что авторы искренне благодарны.

образований флювиогляциальных дельт равен 7,6 , зандров $-7,2$, флювиогляциальных террас - 6,1 и аллювия - 5,6 мм. Общая тенденция улучшения отсортированности материала от краевых флювиогляциальных отложений к приледниковым флювиогляциальным и далее к аллювиальным отмечена Э. Левковым и С. Тихоновым (1972).

Аллювиальные песчано-гравийные отложення среди всех изученных характеризуются несколько повышенным содержанием крупнозернистого гравия и песка, с наименьшим количеством обломков крупнее 70 мм и наиболее постоянным гранулометрическим составом (рис. 1). Такая же закономерность установлена при обобщении результатов разведки месторождений песчано-гравийного материала Литовской ССР (Дварецкас и др., 1976). Аллювиальные песчано-гравийные отложения по отсортированности близки к приледниковым флювиогляциальным, а при размыве речными водами отсортированность материала несколько ухудшается.

По гранулометрическому составу изученные пески можно разделить на две группы. Наиболее широко распространены разнозернистые неоднородные пески с гетерогенным распределением обломков, которые отложены текучими водами. Они представляют внутриледниковые, маргинальные и приледниковые флювиогляциальные, а также аллювиальные песчаные отложения (рис. 3). Более постоянные условия седиментации в бассейнах и переработка обломочного материала ветром способствовали возникновению одномодального распределения зерен в лимногляциальных, прибрежно-морских (подводного склона), пляжевых и эоловых песках. Существенно различающиеся динамика среды осадконакопления, плотность среды седиментации, количество циклов повторной транспортировки, продолжительность и постоянство переработки исходного материала обусловили возникновение разных по гранулометрическому составу песков.

Нанболее разнородными являются пески смешанных камов, озов и краевых флювиогляциальных гряд. Повышенные коэффициенты вариации содержания отдельных фракций показывают, что кроме фракции 0,315-0,2 мм преобладающими часто могут быть мелкозернистая $(0,2-0,1$ мм $)$ или крупнозернистая $(1,0-0,4$ мм) фракции песка. Более постоянным гранулометрическим составом песков в целом, как и гравийного материала, выделяются смешанные камы.

Значительные вариации содержания наиболее мелких фракций в песках краевых флювиогляциальных гряд (рис. 3), а также повышенные их количества свидетельствуют о том, что при образовании указанных отложений сток воды иногда был затруднен. Кроме того, с ледника поступал материал, обогащенный глинистыми частицами, которые вследствие перенасыщенности потоков не успевали вымываться. На более высокое содержание частиц мельче 0,1 мм в отложениях крае- 
вых гряд, чем в остальных флювиогляциальных отложениях Белоруссии, обратил внимание А. Матвеев (1976).

Аллювиальные и приледниковые флювиогляциальные пески отличаются от внутриледниковых и маргинальных песков уменьшенным содержанием частиц мельче 0,14 мм и возрастанием количества частиц фракции 0,315-0,2 мм. В приледниковых условиях песчаный материал переносился на большие расстояния, неоднократно переотлагался, зерна лучше обтирались, и поэтому алевритовые и глинистые частицы хорошо отделялись и выносились за пределы седиментации флювиогляциальных наносов.

Несмотря на то что коэффициенты вариации алевритовых фракций очень велики (рис. 3), ввиду незначительных средних содержаний максимальные встречаемые их значения редко (в зандрах и флювиогляциальные дельтах) достигают средних показателей для песков внутриледникового генезиса. Отмечено, что в различных отдельно взятых регионах механический состав песков краевых флювиогляциальных гряд и приледниковых флювиогляциальных отложений тесно взаимосвязан. Только в последних из-за выноса мелких и алевритовых частиц увеличивается содержание преобладающей $0,315-0,2$ мм и более крупной фракций (Микалаускас и др., 1974).

Приледниковые флювиогляциальные и аллювиальные пески на протяжении всего разреза обладают более постоянным механическим составом (рис. 3) и являются крупнее внутриледниковых-маргинальных. Основная масса песков смешанных камов $(77,4 \%)$ и краевых флювиогляциальных гряд $(66,7 \%)$ имеют коэффициент вариации более $60 \%$. Приледниковые флювиогляциальные пески отсортированы гораздо лучше, так как 66-81\% всех образцов имеют коэффициент вариации менее $70 \%$. Аллювиальные пески рассматриваемого региона формируются за счет переотложения разного материала, поэтому они по гранулометрическим коэффициентам занимают промежуточное положение между указанными выше генетическими разновидностями песков.

Осаждение отложений лимногляциальных камов происходило в спокойной среде (большое содержание алевритовых частиц), однако близость ледовых берегов с моренным материалом способствовала неравномерному распределению зерен крупного и грубого песка. В песках приледниковых лимногляциальных бассейнов частицы крупнее 1 мм отсутствуют, эти пески гораздо лучше промыты (рис. 3).

Наиболее постоянным зерновым составом характеризуются прибрежно-морские (подводного склона) пески, которые являются мелкозернистыми с преобладанием фракции 0,2-0,14 мм (вариация содержания всего $24 \%$ ). В песках у открытых берегов Литвы практически отсутствуют частицы мельче 0,063 мм. В связи с тем, что волны наибольшее воздействие на обломочный материал оказывают в зоне пляжа, здесь из песков почти совсем удалены и зерна фракции $0,14-0,1$ мм. Хуже отсортирован материал в узких бухтах Эстонского побережья, однако мы не располагаем точными статистическими данными для сравнения.

Неоднократно доказывалось (Сидоренко, 1956; Айнемер, Шванов, 1968), что любые эоловые пески всегда несут следы структуры исходного материала, поэтому их целесообразно изучать без отрыва от исходных пород. Они являются нанболее однородными и имеют постоянный гранулометрический состав; лучше всего отсортированы эоловые пески морского побережья. Каждая разновидность эоловых песков различается по крупности (рис. 3,4$)$ в зависнмости от исходных пород.

При перевеивании исходных песков флювиогляциальных террас со- 
циентов имеет большое значение при изучении процесса механической дифференциации обломочного материала и восстановлении условий формирования песчано-гравийных и песчаных отложений.

\section{ЛИТ Е Р А Т У Р А}

А й нем е р А. И., Ш ван о в В. Н. О фациальной значимости гранулометрического состава песчаных эоловых отложений. - Тр. ВСЕГЕИ, Нов. сер., 1968, т. 150, c. $98-103$.

Биргер А. Я., К арпов В. М., Клепиков В. С., Куршс В. М., Скурбе Д. Э., Смирнов В. М., Стинкуле А. В., Шарак К. А. Минеральное сырье Латвии для промышленности строительных материалов. Рига, 1977.

Горелик 3. А., Мишагова Э. Д., Л евков Э. А. Пески БССР и их промышленное использование. Минск, 1961.

Д ан и л ан с И. Я. Четвертичные отложения Латвин. Рига, 1973.

Д в а рецкас В., Юргайти с А., Ю озапа вичюс Г. Методические особенности геоморфологических и литологических исследований флювиогляциальных и аллювиальных отложений. - В кн.: Методика и интерпретация результатов минералогических и геохимических исследований. Вильнюс, 1976.

К уршс В. М. Минеральнсе сырье Латвии для производства нерудных строительных материалов. Рига, 1963.

Л ев ков Э. А., Т и х он о в С. А. Основные особенности гранулометрического состава песчано-гравийно-галечных отложений антропогена Белоруссии. - В кн.: Вопросы геологии антропогена. Бел.НИГРИ. М., 1972, вып. 2, с. 96-98.

М а т в е е в А. В. Ледниковая формация антропогена Белоруссии. Минск, 1976.

Микал аускас А., Ненартавтчене Д., С аусайтис И., Юозапавич ю с Г., Ю ргай т и с А. Строение, литогенез и промышленная оценка отложений Дайнавской песчаной равнины. - В кн.: Предфронтальные краевые ледниковые образования. Вильнюс, 1974, с. 158-178.

Р а ук а с А. Плейстоценовые отложения Эстонской ССР. - Таллин, 1978.

Р аука с А., Р яхни Э., Мийдел А. Краевые ледниковые образования Северной Эстонии. Таллин, 1971.

С.и дорен ко А. В. Эоловая дифференциация вещества в пустыне. - Изв. АН СССР, сер. геогр., 1956, № 3, с. 3-22.

Ю р га й т и с А. А. Генетические типы и литология песчано-гравийных отложений Литовской ССР. - Тр. институга геологии (Вильнюс). Вильнюс, 1969, вып. 9.

L inčius, A., Ug i ňi us, A. Baltijos jūros kranto zonos smèlis tarp Kopgalio ir Juodkrantès (litologinè charakteristika). - Lietuvos geologijos moksliniọ tyrimo instituto darbai, 19 t., Vilnius, 1972, psl. $7-26$.

\section{Литовский научно-исследовательский} геологоразведочный институт

Поступила в редакцию $15 /$ II 1979

Всесоюзный научно-исследовательский институт морской геологии и геофизики

Тартуский государственный университет

A. JURGAITIS, G. JUOZAPAVICIUS,

V. KLEPIKOV, V. KALM

\section{BALTIMAADE JA VALGEVENE POOHJAOSA KVATERNAARSETE LIIVA-KRUUSA- JA LIIVASETETE GRANULOMEETRILINE DIFERENTSIATSIOON}

-Mõhnade, ooside, marginaalsete fluvioglatsiaalsete ahelike, sandurite, fluvioglatsiaalsete deltade ja terrasside, alluviaalsete, limnoglatsiaalsete tasandike, mereliste ja eooliliste setete granulomeetrilise koostise ning jaotumuse pōhjal on järeldatud, et igale settetüübile on 'omased kindlad seaduspärasused, mille alusel on võimalik selgitada setete kujunemistingimusi. 
A. JURGAITIS, G. JUOZAPAVICIUS,

V. KLEPIKOV, V. KALM

\section{GRANULOMETRIC DIFFERENTIATION OF THE QUATERNARY GRAVELLY AND SANDY DEPOSITS IN THE BALTIC AREA AND NORTHERN BYELORUSSIA}

The granulometric composition of sandy-gravelly deposits and sands in various coastal and marine formations has been studied. Statistical characteristics of the debris distribution curve (mean grain size, sorting and variation coefficients) and also the estimation of the content variability of granulometric fractions throughout the massif contribute greatly to the determination of the processing degree of the original material and to the elucidation of its deposition conditions.

\section{Десять лет Прибалтийской региональной межведомственной стратиграфической комиссии (РМСК)}

Прибалтийска́я РМСК была учреждена 31 января 1969 г. постановлением Межведомственного стратиграфического комитета СССР. Основной задачей этой комиссии является решение различных вопросов региональной стратиграфин, связанных прежце всего с разработкой стратиграфической основы для крупномасштабной геологической съемки. Комиссия состоит из республиканских подкомиссий и стратиграфических секций, объединяет всех стратиграфов Прибалтики. Основная форма работы комиссии ежегодные тематические пленумы. Подкомиссии осуществляют «стратиграфическую службу» в республиках, секции проводят совместные полевые исследования, семинары, симпозиумы. Существует подкомиссия по терминологии и номенклатуре.

Деятельность Прибалтийской PMCK за 10 лет ее существования была плодотворной. Важнейшими достижениями можно считать создание теоретической основы региональной стратиграфии Прибалтики, разработку критериев региональных и местных стратиграфических подразделений, структурно-фациальное районирование геологических систем. Основным нтогом этой работы было создание унифицированных региональных стратиграфических схем всех геологических систем. Указанные схемы были приняты в мае 1976 г. на Прнбалтийском межведомственном стратиграфическом совещании в Вильнюсе и утверждены в январе 1977 г. Межведомственным стратиграфнческим комитетом СССР. Новые детальные схемы опубликованы в 1978 г. и предназначаются для крупномасштабного геолого-гидрогеологического картирования, детальных геологоразведочных работ и других видов специальных и сводных геологических исследований.

Методы создания детальной стратиграфической основы для геологических исследований Прнбалтики экспонировались в 1979 г. в основной экспозиции павильона «Геология на Выставке достижений народного хозяйства СССР. За эту работу шесть стратиграфов Прибалтики были награждены медалями ВДНХ. Выход в свет методических рекомендаций по составлению легенд крупномасштабных геологических карт, разработанных по инициативе PMCK коллективом ученых и практиков, облегчит использование стратиграфической основы.

В своей работе Прибалтийская РМСК пользуется всемерной поддержкой научных геологических институтов и университетских кафедр, производственных геологических управлений Прибалтийских республик, за что выражает им глубокую признательность.

В дальнейших планах Прибалтийской стратиграфической комиссии намечаются изучение стратотипов стратонов и их границ и организация их охраны, составление стратиграфического справочника Прибалтики, уточнение схем корреляции и унификации стратиграфических подразделений.

А. ГРИГЯЛИС 